\title{
A New Hybrid Approach for the Thermo-acoustic Modelling of Engine Exhaust Systems
}

\author{
R. N. Hota and M. L. Munjal ${ }^{\dagger}$ \\ Facility for Research in Technical Acoustics, Department of Mechanical Engineering, \\ Indian Institute of Science, Bangalore-560012, India
}

(Received 22 December 2003; accepted 23 June 2004)

\begin{abstract}
The time-domain method of characteristics and the frequency-domain linear acoustics method are the two different methods of thermo-acoustic modelling of engine exhaust systems in order to predict exhaust noise. To overcome the disadvantages of both the time-domain and the frequency-domain approaches, a hybrid approach has been developed which couples the acoustical description of the muffler piping system to the acoustic source more realistically than the usual time invariant linear model. A time domain model and the corresponding frequency domain model of a linear dynamical system are interrelated by the Fourier transform pair. In the present work, the cylinder/cavity is analysed in the time domain to calculate exhaust mass flux history at the exhaust valve by means of the method of characteristics, solving a number of equations simultaneously at the valve junction. This analysis has been done by making use of an interrelationship between progressive wave variables of linear acoustic theory and those of the method of characteristics. In this approach, nonlinear propagation in the exhaust pipe is neglected and radiation impedance at the end of the exhaust tail pipe is duly taken into account. Apart from this, actual reflection of the forward wave due to the presence of muffler is incorporated to make the analysis more realistic. Damping effects present in the fluid have also been taken into account. Computational results have been corroborated by experimental data for a single-cylinder, four-stroke cycle diesel engine.
\end{abstract}

${ }^{\dagger}$ Fellow of the International Institute of Acoustics and Vibration (IIAV)

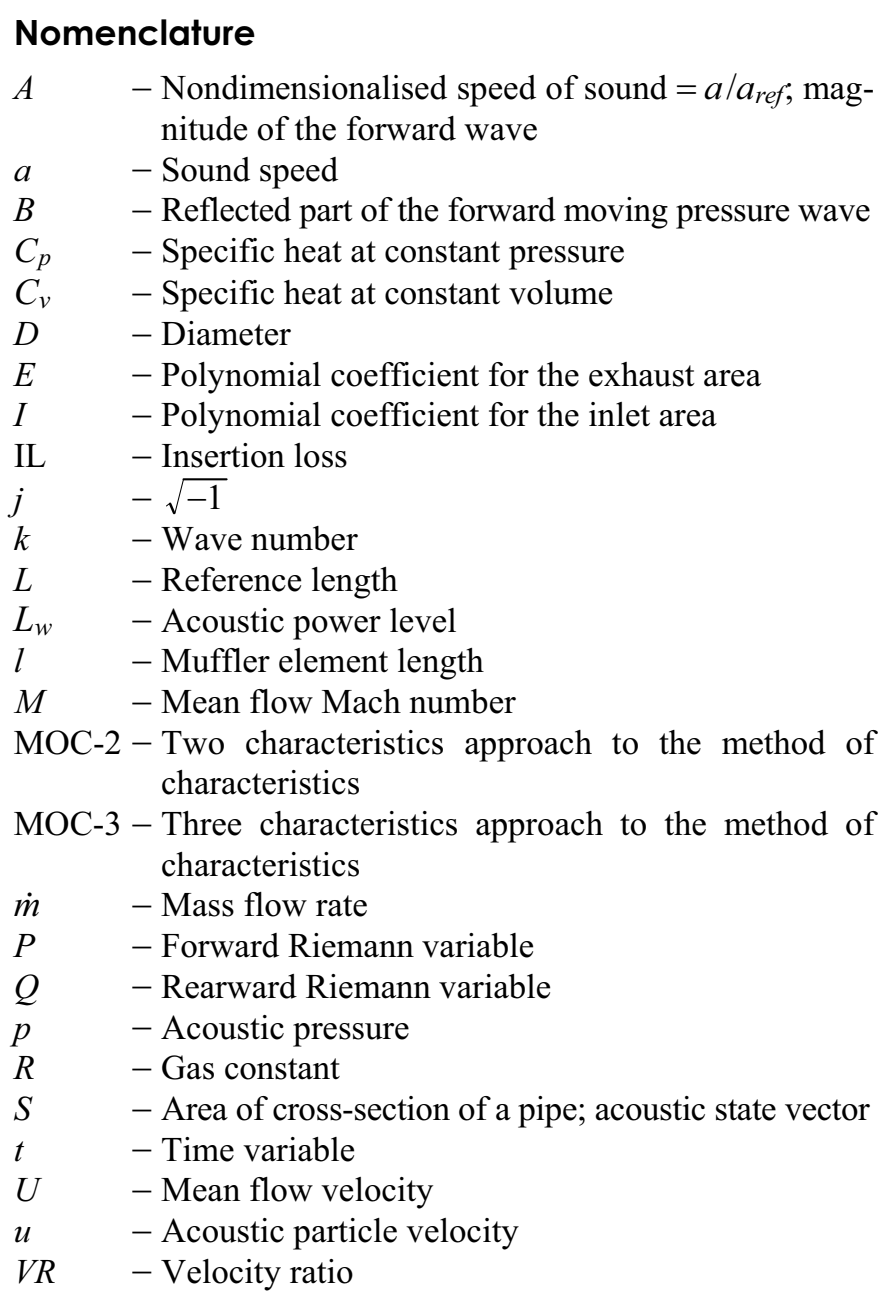

$v \quad-$ Acoustic mass velocity

$W \quad-$ Acoustic power

$X \quad$ - Nondimensionalised space variable

$x \quad$ - Space coordinate

$Y \quad-$ Characteristic impedance of a pipe

Z $\quad-$ Nondimensionalised time variable; impedance

$z \quad-$ Space coordinate

$\gamma \quad-$ Ratio of specific heats

$\theta \quad-$ Crank angle

$\rho \quad-$ Density

$\omega-$ Circular frequency

$L_{c} \quad$ - Connecting rod length

RBP - Rated Brake Power

CR - Compression Ratio

\section{INTRODUCTION}

Noise pollution from automobiles has become a serious problem. Hence, the design and analysis of mufflers for engine exhaust systems are active areas of research. In order to create a suitable design for a muffler, the noise generating source has to be analysed integrally with the muffler. Generally, mufflers are modelled in the frequency domain, making use of the transfer matrix method. ${ }^{1}$ This method requires a prior knowledge of the source characteristics as a function of frequency, which is still a challenge. In fact, in view of the strong time variance and nonlinearity of engine exhaust sources, there are serious doubts about the existence of unique source characteristics. ${ }^{2}$ Such a source, with varying mass flows through the valves, can be dealt with best in the time domain. The time domain analysis, based on the method of characteristics, is complete in itself but is very cumber-

International Journal of Acoustics and Vibration, Vol. 9, No. 3, 2004 (pp 129-138) 